\title{
A modified calculation model for groundwater flowing to horizontal seepage wells
}

\author{
Wei Wang*, Peng Chen, Qingqing Zheng, Xinyu Zheng and Kunming Lu \\ School of Environmental Science and Engineering, Chang'an University, Xi'an, Shaanxi 710054, \\ People's Republic of China. \\ *Corresponding author.e-mail: wangweichd@chd.edu.cn
}

\begin{abstract}
The simulation models for groundwater flowing to horizontal seepage wells proposed by Wang and Zhang (2007) are based on the theory of coupled seepage-pipe flow model which treats the well pipe as a highly permeable medium. However, the limitations of the existing model were found during applications. Specifically, a high-resolution grid is required to depict the complex structure of horizontal seepage wells; the permeability of the screen or wall material of radiating bores is usually neglected; and the irregularly distributed radiating bores cannot be accurately simulated. A modified calculation model of groundwater flowing to a horizontal seepage well is introduced in this paper. The exchange flow between well pipe and aquifer couples the turbulent flow inside the horizontal seepage well with laminar flow in the aquifer. The modified calculation model can reliably calculate the pumpage of a real horizontal seepage well. The characteristics of radiating bores, including the diameter, the permeability of screen material and irregular distribution of radiating bores, can be accurately depicted using the modified model that simulates the scenario in which several horizontal seepage wells work together.
\end{abstract}

\section{Introduction}

A horizontal seepage well is a complex construction which is used to acquire relatively clean water that has been filtered through natural alluvial deposits in a riverbed ( $\mathrm{Li}$ and Yang 2003; Fu et al. 2004; Wang and Zhang 2007). It consists of interconnected vertical well, galleries, chambers and smalldiameter radiating bores (the term 'well pipe' is used hereafter to describe this four-part combination of what constitutes a horizontal seepage well). Different horizontal seepage wells may have different number of chambers. Normally there are several bores radiating from the top and each side of the chamber. These radiating bores partially penetrate the main aquifer that is beneath the riverbed.
Figure 1 is the sketch of a typical horizontal seepage well located in Wulidian water-supply field in the Wuding river valley of Suide City at northern Shaanxi Province in China. It was used as an example by Wang and Zhang (2007) and will also be used as an example in this study. In this figure, the capital letters represent the chambers; the dimensions of each chamber are $3 \times 3 \times 3.5 \mathrm{~m}$. Each gallery connecting two adjacent chambers is about $50 \mathrm{~m}$ in length; the cross section of the gallery is $1.7 \mathrm{~m}$ in height and $1.5 \mathrm{~m}$ in width. The diameter of the vertical well is $3 \mathrm{~m}$ and the diameter of each radiating bore is approximately $0.1 \mathrm{~m}$.

Horizontal seepage well was first applied in Sichuan Province, China in 1992 and now is being widely used in western China, especially in arid and

Keywords. Exchange flow; couple key; coupled seepage-pipe flow model; horizontal seepage well; Darcy-Weisbach equation; hydrology; modelling; coupled systems. 

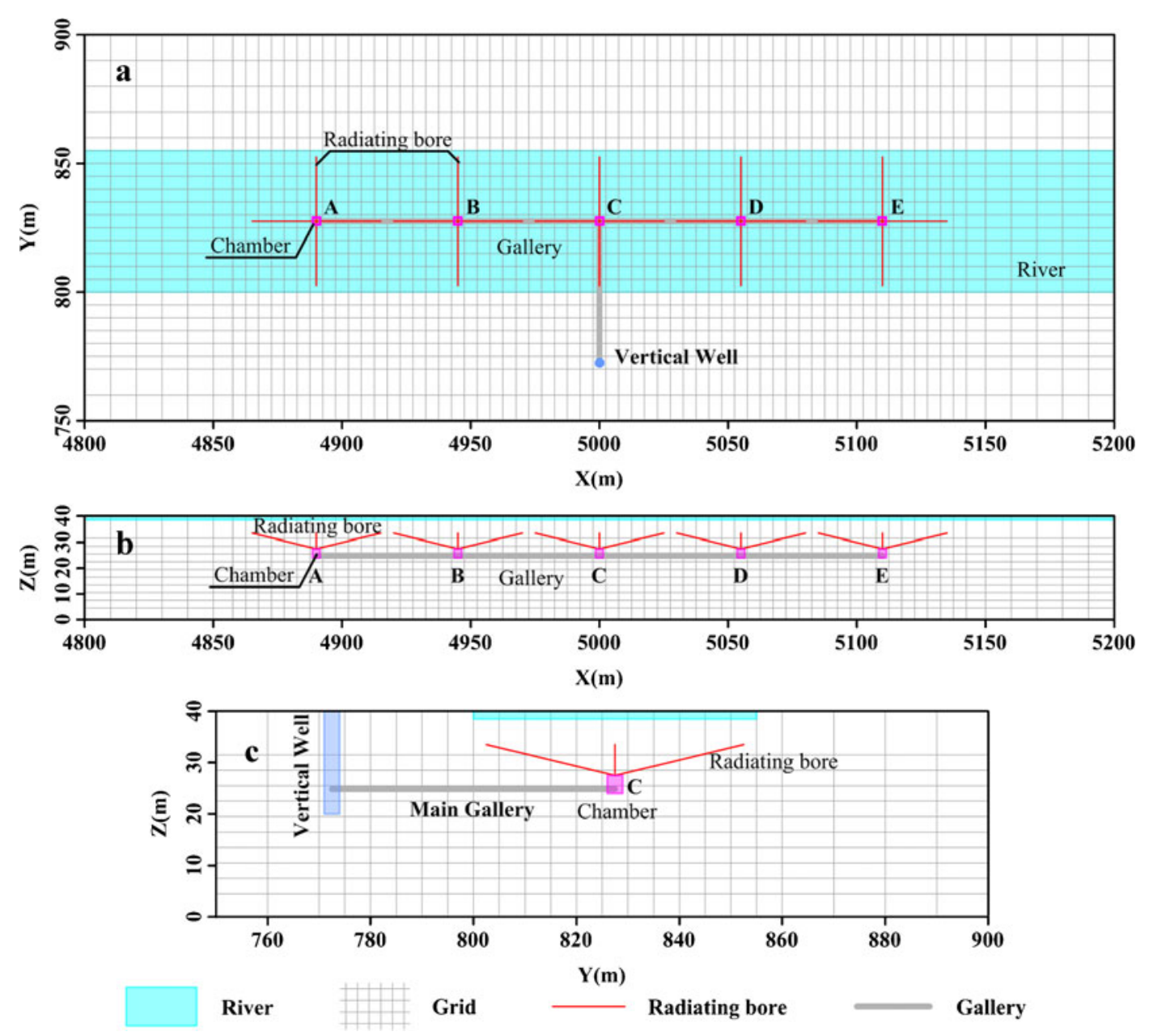

Figure 1. Sketch of a horizontal seepage well structure in (a) plan view, (b) XZ cross section for chambers and (c) YZ cross section for chamber C.

semi-arid area with great success so far. Because the yield of a traditional borehole is usually less than $100 \mathrm{~m}^{3} / \mathrm{d}$, many river valleys in the Loess plateau are not suitable to be developed as watersupplying field. However, the use of horizontal seepage well as water-supplying structure in these river valleys are indeed providing more and more water. For example, a horizontal seepage well can yield more than $16,000 \mathrm{~m}^{3} / \mathrm{d}$ fresh water in Yuxi river valley, $4500 \mathrm{~m}^{3} / \mathrm{d}$ fresh water in Wuding river valley and $2000 \mathrm{~m}^{3} / \mathrm{d}$ in Boniuchuan river valley. All these valleys are located in Loess plateau of northern Shaanxi, China.

The existing calculation model for single horizontal seepage well was built by Wang and Zhang (2007) based on theory of coupled seepage-pipe flow and equivalent hydraulic conductivity (Chen 1995; Chen and Lin 1998a, 1998b; Chen and Jiao 1999; Chen et al. 2003). In this model, the well-aquifer system is treated as a heterogeneous medium where the well pipe is treated as a highly permeable medium and the boundary of the whole horizontal seepage well is moved to the vertical well. Horizontal seepage well pumping is thus simplified as a problem of a single well working in a heterogeneous medium. The hydraulic conductivity of the well pipe is formulized using equivalent hydraulic conductivity derived from pipe flow hydraulics.

This model has been successfully applied in the evaluation and design of horizontal seepage wells. The limitations of this existing model can be summarized as follows:

- A high-resolution cubic cell grid is necessary to depict the complex structure of horizontal seepage wells and to calculate the flow field generated by the pumping of horizontal seepage well. Therefore, the model involves a large number of nodes. When there are two or more horizontal seepage wells working together, there will be too many nodes for effective calculation on a personal computer. 
- When calculating the exchange flow between pipe and aquifer, the permeability of the screen or wall material of radiating bores cannot be taken into account.

- It is extremely difficult to simulate the radiating bores that are irregularly distributed.

These limitations will restrict the extensive use of the existing horizontal seepage well model.

The goal of this paper is to present a modified calculation model, in which the method of coupling a single continuum model with a discrete conduit network model is used instead of treating the well pipe as a highly permeable medium. Thus this method is able to overcome all the abovementioned limitations. We also perform a case study to demonstrate the merits of the modified model.

\section{Modified model}

Models for groundwater flow in carbonate aquifer in karst terrain (Clemens et al. 1996; Adams and Parkin 2002) are similar to those for horizontal seepage wells and they can be used as references for developing the modified calculation model for horizontal seepage wells. In these models, karst conduit system is conceptualized as a discrete conduit network. The coupling of a single continuum model with a discrete conduit network model allows the detailed information about the conduits to be integrated in areas where the geometry of the conduits may be known, and provides a more physically representative model in these areas (Shoemaker et al. 2007).

To overcome the limitations of existing horizontal seepage well models, the method of coupling a single continuum model with a discrete conduit network model is used in this study. In the modified model for a horizontal seepage well, the well pipe system is conceptualized as a discrete conduit network that consists of pipes and nodes (Shoemaker et al. 2007). The flow rate in well pipe and the exchange flow rate between well pipe and aquifer can be calculated respectively, and thus the exchange flow rate between well pipe and aquifer for coupling can be chosen.

\subsection{Equation for seepage flow}

When the groundwater flow laminarly through porous media at low Reynolds numbers, the threedimensional movement of groundwater with constant density and viscosity through porous media can be described by the partial-differential equation (Bear 1972):

$$
\begin{aligned}
& \frac{\partial}{\partial x}\left(K_{x x} \frac{\partial H}{\partial x}\right)+\frac{\partial}{\partial y}\left(K_{y y} \frac{\partial H}{\partial x}\right)+\frac{\partial}{\partial z}\left(K_{z z} \frac{\partial H}{\partial x}\right) \\
& \quad+W=S_{s} \frac{\partial H}{\partial t}
\end{aligned}
$$

where $K_{x x}, K_{y y}$ and $K_{z z}$ are values for hydraulic conductivity $\left[\mathrm{LT}^{-1}\right]$ along the $\mathrm{x}, \mathrm{y}$, and $\mathrm{z}$ axes, respectively; $H$ is head [L]; $W$ is a volumetric flux per unit volume $\left[\mathrm{T}^{-1}\right] ; S_{s}$ is specific storage $\left[\mathrm{L}^{-1}\right]$; $t$ is time $[\mathrm{T}]$. For steady state simulation, the right term of equation (1) should be zero.

\subsection{Pipe flow hydraulics}

When a horizontal seepage well is pumping, several flow regimes may coexist in the well-aquifer system at the same time (Chen et al. 2003; Wang and Zhang 2007). Since the well pipe (consisting of vertical well, galleries, chambers and radiating bores as shown in figure 1) has a relatively large hydraulic radius, the flow regime in the well pipe is often a turbulent flow with larger Reynolds numbers. In the well pipe, the relationship between hydraulic head loss and flow velocity may consists of five components (Chen et al. 2003; Wang and Zhang 2007): laminar flow, in which the hydraulic head loss is in proportion to the flow velocity $u$; smooth turbulent flow, in which the hydraulic head loss is in proportion to $\mathrm{u}^{1.75}$; turbulent flow, in which the hydraulic head loss is in proportion to $\mathrm{u}^{2}$; and two transitional flows among the three components.

The well pipes are assumed to be permanently saturated and the compressibility of the fluid is neglected. According to Darcy-Weisbach equation (Munson et al. 1998; Li and Xu 2000), the following formula can be derived:

$$
\begin{gathered}
\Delta H=f \cdot \frac{l}{d} \cdot \frac{u^{2}}{2 g} \\
d=\frac{4 A}{\chi}
\end{gathered}
$$

where $f$ is the coefficient of friction [unit-less]; $l$ is the length $[\mathrm{L}]$ of flow path; $u$ is the average flow velocity $\left[\mathrm{LT}^{-1}\right]$ in the well pipe; $g$ is the gravity acceleration $\left[\mathrm{LT}^{-2}\right], d$ is the equivalent diameter $[\mathrm{L}]$ of the well pipe, $A$ is the area $\left[\mathrm{L}^{2}\right]$ of flow section in well pipe; $\chi$ is the wetted perimeter $[\mathrm{L}]$ of well pipe. Then the equation (2) can be rewritten as:

$$
u=\left(\frac{2 g d}{f} \cdot \frac{\Delta H}{l}\right)^{\frac{1}{2}}
$$


Then the flow rate $Q_{p}$ in the well pipe with turbulent flow can be calculated as following:

$$
Q_{p}=u A=\frac{\pi d^{2}}{4}\left(\frac{2 g d}{f} \cdot \frac{\Delta H}{l}\right)^{\frac{1}{2}}
$$

The calculation of flow rate in the well pipes requires the coefficient of friction. For laminar flow, coefficient of friction can be calculated as follows (Munson et al. 1998; Li and Xu 2000):

$$
f=\frac{64}{R e}=\frac{64 v}{u d}
$$

where $R e=u d / v$ is Reynolds number [unit-less], $v$ is kinematic viscosity of water $\left[\mathrm{ML}^{-1} \mathrm{~T}^{-1}\right]$.

Upon substitution of equation (5) into equation (4), a new equation is obtained:

$$
Q_{p}=\frac{\pi d^{2}}{4} \frac{d^{2} g}{32 v} \frac{\Delta H}{l}
$$

For turbulent flow with $3000<R e<100,000$, the coefficient of friction is given as follows ( $\mathrm{Li}$ and $\mathrm{Xu}$ 2000):

$$
f=\frac{0.316}{R e^{0.25}} .
$$

The substitution of equation (7) into equation (4) yields:

$$
Q_{p}=\frac{\pi d^{2}}{4} \frac{2 g d}{0.316}\left(\frac{d}{v}\right)^{0.25}\left(\frac{1}{u}\right)^{0.75} \frac{\Delta H}{l}
$$

This equation shows that the hydraulic head loss $\Delta H$ is proportion to $u^{1.75}$ when $3000<R e<$ 100,000 .

For turbulent flow with $R e>100,000$, coefficient of friction is independent of Reynolds number, but dependent on wall coarseness of well pipe (Munson et al. 1998; Li and Xu 2000):

$$
f=\frac{1}{4}\left(\log _{10} 3.71 \frac{d}{e}\right)^{-2}
$$

where $e$ is the coarseness degree of inner wall of well pipe $[\mathrm{L}]$.

Substitution of equation (9) into equation (4) yields:

$$
Q_{p}=\frac{\pi d^{2}}{4} 8 g d \cdot\left(\log _{10} 3.71 \frac{d}{e}\right)^{2} \cdot \frac{1}{u} \frac{\Delta H}{l}
$$

This equation shows that the hydraulic head loss $\Delta H$ is proportionate to $u^{2}$ when $R e>100,000$.
Equations (6), (8) and (10) indicate that the hydraulic head loss is in proportion to the flow velocity $u$ for laminar flow, in proportion to $u^{1.75}$ for smooth turbulent flow and in proportion to $u^{2}$ for turbulent flow, respectively.

The relationship between seepage velocity $v$ and real flow velocity $u$ in the pores of porous media is $v=n u$, where $n$ is the medium porosity [unit-less]. In the well pipe, $n=1$, and hence $v=u$.

In order to calculate the flow rate in the well pipe $Q_{p}$, the average pipe flow velocity $u$, Reynolds number and coefficient of friction $f$ are required. Reynolds number $R e$ depends on the average flow velocity $u$; the average flow velocity $u$ depends on the coefficient of friction $f$; the coefficient of friction $f$ depends on the Reynolds number Re. Thus, an iterative solver is employed to calculate these three variables together with the flow rate in the well pipe $Q_{p}$.

\subsection{Exchange flow rate between well pipe and aquifer}

To describe the exchange flow rate between the well pipe and the aquifer and also to reflect the skin effect of pipe, the simple linear equation can be conceptualized as a third kind boundary:

$$
Q_{e}=C\left(H_{p}-H\right)
$$

where $Q_{e}$ is the exchange flow rate $\left[\mathrm{L}^{3} \mathrm{~T}^{-1}\right]$ between well pipe and aquifer; $C$ is the conductance $\left[\mathrm{L}^{2} \mathrm{~T}^{-1}\right]$ of pipe screen material; $H_{p}$ is the head $[\mathrm{L}]$ of pipe flow. According to this equation, a negative value of $Q_{e}$ indicates that the exchange flow is from the aquifer into the well pipe; conversely, a positive value of $Q_{e}$ indicates that the exchange flow is from the well pipe into the aquifer. The conductance of the pipe screen material can be calculated as follows:

$$
C=\frac{K_{p} D l}{M_{p}}
$$

where $K_{p}$ is the hydraulic conductivity of the pipe screen material; $M_{p}$ is the thickness [L] of the pipe screen material; $D$ is the wetted perimeter of pipe; $l$ is the length $[\mathrm{L}]$ of pipe.

The sum of inflow and outflow at any node $i$ of the network should equal to zero

$$
\sum_{j=1}^{n_{i}} Q_{p_{i, j}}+Q_{e_{i}}=0
$$

where $n_{i}$ denotes the number of nodes connected to node $i . j$ is the sequence number of nodes 
connected to node $i$. Combining equations (6), (8), (10) and (11), we have:

$$
\begin{aligned}
& \sum_{j=1}^{n_{i}} \begin{cases}\frac{\pi d_{i j}^{2}}{4} \frac{d_{i j}^{2} g}{32 v} \frac{\Delta H_{i j}}{l_{i j}} & \text { laminar flow } \\
\frac{\pi d_{i j}^{2}}{4} \frac{2 g d_{i j}}{0.316}\left(\frac{d_{i j}}{v}\right)^{0.25}\left(\frac{1}{u_{i j}}\right)^{0.75} \frac{\Delta H_{i j}}{l_{i j}} & \text { smooth turbulent flow } \\
\frac{\pi d_{i j}^{2}}{4} 8 g d_{i j} \cdot\left(\log _{10} 3.71 \frac{d_{i j}}{e_{i j}}\right)^{2} \cdot \frac{1}{u_{i j}} \frac{\Delta H_{i j}}{l_{i j}} & \text { rough turbulent flow }\end{cases} \\
& +C_{i}\left(H_{p_{i}}-H_{i}\right)=0
\end{aligned}
$$

Through combination of equation (14) of $n$ nodes in the network, a system of $n$ nonlinear equations with $n$ nodes of unknown head can be assembled. This system can be solved by Newton-Raphson iterations (Steffen 2006). Initial guess for node heads can be obtained by solving the system (14) in laminar flow conditions in all pipes.

The combined equations of pipe flow and exchange flow can be solved using numerical method for a discrete grid and a discrete pipe system. By choosing the exchange flow rate between pipe and aquifer as the coupled key point, the flow law in 5 flow regimes (1 laminar flow area in the aquifer and 4 turbulent flow areas in the well pipe) of well pipe system can be described using head dependence boundary. By this means, the pipe flow in the well pipe can be coupled with the seepage flow in the aquifer. Accordingly, the steady-state mathematic model is developed for groundwater flowing to the horizontal seepage well under a river valley. In this model, the source and sink except for the river leakage and pumpage are neglected, so the water table is a flow plane in steady-state flow:

$$
\begin{aligned}
& \left\{\begin{array}{lc}
\frac{\partial}{\partial x}\left(K_{x x} \frac{\partial H}{\partial x}\right)+\frac{\partial}{\partial y}\left(K_{y y} \frac{\partial H}{\partial y}\right)+\frac{\partial}{\partial z}\left(K_{z z} \frac{\partial H}{\partial z}\right)=0 \quad(x, y, z) \in D \\
\left.H(x, y, z)\right|_{\Gamma_{1}}=H_{1}(x, y, z) & \text { constant head boundary } \\
\left.\frac{\partial H}{\partial \mathbf{n}}\right|_{\Gamma_{2}}=q & \text { constant flux boundary } \\
\frac{K_{r}}{M_{r}}\left(H_{r}-H\right)=q_{r} & \text { river boundary } \\
Q_{e}=C\left(H_{p}-H\right) & \text { exchange flow between pipe and aquifer } \\
Q_{p}=\left\{\begin{array}{cc}
\frac{\pi d^{2}}{4} \frac{d^{2} g}{32 v} \frac{\Delta H}{l} & \text { Laminar flow } \\
\frac{\pi d^{2}}{4} \frac{2 g d}{0.316}\left(\frac{d}{v}\right)^{0.25}\left(\frac{1}{u}\right)^{0.75} \frac{\Delta H}{l} & \text { smooth turbulent flow } \\
\frac{\pi d^{2}}{4} 8 g d \cdot\left(\log _{10} 3.71 \frac{d}{e}\right)^{2} \cdot \frac{1}{u} \frac{\Delta H}{l} & \text { rough turbulent flow } \\
H^{2} &
\end{array}\right\} \text { pipe flow }
\end{array}\right. \\
& \left.\begin{array}{l}
H=z \\
\frac{\partial H}{\partial \mathbf{n}_{p}}=0
\end{array}\right\} \\
& \left.\begin{array}{l}
H(x, y, z)=H_{s} \\
q_{s}(x, y, z)=Q_{s}
\end{array}\right\} \quad \text { vertical well boundary, }\left\{\begin{array}{lll}
\text { const } & \text { drawdown } & \text { pumping } \\
\text { const } & \text { flowrate } & \text { pumping }
\end{array}\right.
\end{aligned}
$$


where $H_{1}$ is the head of first type boundary; $q$ is the specific flow rate per unit area $\left[\mathrm{LT}^{-1}\right]$ of the second kind boundary; $K_{r}$ is the vertical hydraulic conductivity of medium in river bed; $q_{r}$ is the specific river leakage $\left[\mathrm{LT}^{-1}\right] ; M_{r}$ is the thickness [L] of medium in river bed; $\mathbf{n}$ is the exterior normal vector of the second boundary; $\mathbf{n}_{p}$ is the exterior normal vector of the water table; $D$ is the study domain. This model can be solved numerically and an iterative scheme must be employed to calculate the average pipe flow velocity $u$, Reynolds number and coefficient of friction $f$. After this, pipe head and the exchange flow rate between pipe and aquifer can be computed.

\section{Numerical simulation with the modified calculation model}

To verify the reliability of the modified calculation model for horizontal seepage well, a real horizontal seepage well mentioned by Wang and Zhang (2007) can be chosen for the test. The mathematical model of this problem can be described by equation (15), and solved by a three dimensional finite difference numerical method as done by Wang and Zhang (2007).

The horizontal seepage well studied is located at a river valley in Loess plateau. The model domain is conceptualized as a rectangle river valley, which is $10 \mathrm{~km} \mathrm{E}-\mathrm{W}$ (along the river), and $1 \mathrm{~km} \mathrm{~N}-\mathrm{S}$; the width of river is $50 \mathrm{~m}$. The aquifer consists of Quaternary alluvium and a weathered zone of Triassic sandstone and mudstone. The total thickness of aquifer (both Quaternary and weathered Triassic sandstone) is $8.50 \mathrm{~m}$, with $5.25 \mathrm{~m} / \mathrm{d}$ horizontal hydraulic conductivity and $1.00 \mathrm{~m} / \mathrm{d}$ vertical hydraulic conductivity. To simulate the three-dimensional flow field around the horizontal seepage well, the total thickness of model layers, which includes part of the Triassic rock under the weathered zone, is considered as $40 \mathrm{~m}$; the thickness of Triassic rock is $31.50 \mathrm{~m}$, and its hydraulic conductivity is $0.233 \mathrm{~m} / \mathrm{d}$. The Triassic rock is considered as an aquiclude and forms the base of the aquifer (depth from ground surface is greater than $40 \mathrm{~m}$ ) due to its compact formation and lack of fissures. The river is treated as a head-dependent boundary, where the thickness of deposit in the riverbed is $1 \mathrm{~cm}$ and its vertical hydraulic conductivity is $0.025 \mathrm{~m} / \mathrm{d}$ according to the field seepage tests. The river stage is also $40 \mathrm{~m}$ which is the same as the eastern and western boundaries. The top of the model domain is the water table. No more sources and sinks are considered besides the river leakage and pumpage. More details of the hydrogeologic condition can be found in Wang and Zhang (2007).
In the existing model, a high-resolution cubic cell grid is applied to the model domain to reflect the complex structure of horizontal seepage well. The model has 207 columns, 60 rows, and 12 layers with the minimum interval of $0.75 \mathrm{~m}$ in the horizontal plane near the horizontal seepage well. Considering the fact that the diameter of radiating bores is only about $0.1 \mathrm{~m}$, a weighted average hydraulic conductivity taking account of the cross sectional area of radiating bores is employed as the vertical hydraulic conductivity in the area where the radiating bores are distributed to simulate the effect of a radiating bore within the grid (with minimum interval $0.75 \mathrm{~m}$ ). The steady state flow field calculated by the existing model is shown in figure 2. It also shows the location of the galleries, the chambers and the vertical well. (a) is the plain view showing where the galleries are located in the $\mathrm{x}$ and $\mathrm{y}$ planes; (b) is the cross sectional view showing where the underground chambers are located in the $\mathrm{x}$ and $\mathrm{z}$ planes; (c) is the cross sectional view showing where the vertical well is located in the $y$ and $\mathrm{z}$ planes.

To demonstrate the advantages of the modified calculation model, the model domain can be discretized into 99 columns, 41 rows, and 11 layers with the minimum interval of $5 \mathrm{~m}$ in the horizontal plane near the horizontal seepage well (figure 1). The well pipe system of horizontal seepage well which consists of interconnected vertical well, galleries, chambers and small diameter radiating bores is treated as a set of discrete pipes connected by nodes. Each node is located at the center of a finite-difference cell in horizontal direction, and may have different elevation depending on the vertical position of well pipe. Each node can connect to adjacent nodes by pipes along $\mathrm{X}, \mathrm{Y}$ direction or diagonally within and between adjacent model layers. There can be only one node within a finitedifference cell. Under constant drawdown pumping, the nethermost cell of vertical well is set as a constant head cell. The end of discrete conduit system of well pipe is located in this constant head cell and has the same hydraulic head as the constant head cell does.

There are 25 radiating bores in total. Specifically, there are 5 radiating bores in each chamber with one radiating bore on each side and one radiating bore in the center of the ceiling. Considering the fact that the inner face of the galleries, chambers and vertical well is lined, the hydraulic conductivity of pipe lined wall is set at a small value at $0.005 \mathrm{~m} / \mathrm{d}$ in this model. Since the screens are placed on the radiating bores without casing, the hydraulic conductivity of pipe screen is set according to the corresponding aquifer material. It is $5.25 \mathrm{~m} / \mathrm{d}$ when the radiating bores are open to the Quaternary system and is $0.233 \mathrm{~m} / \mathrm{d}$ when the 

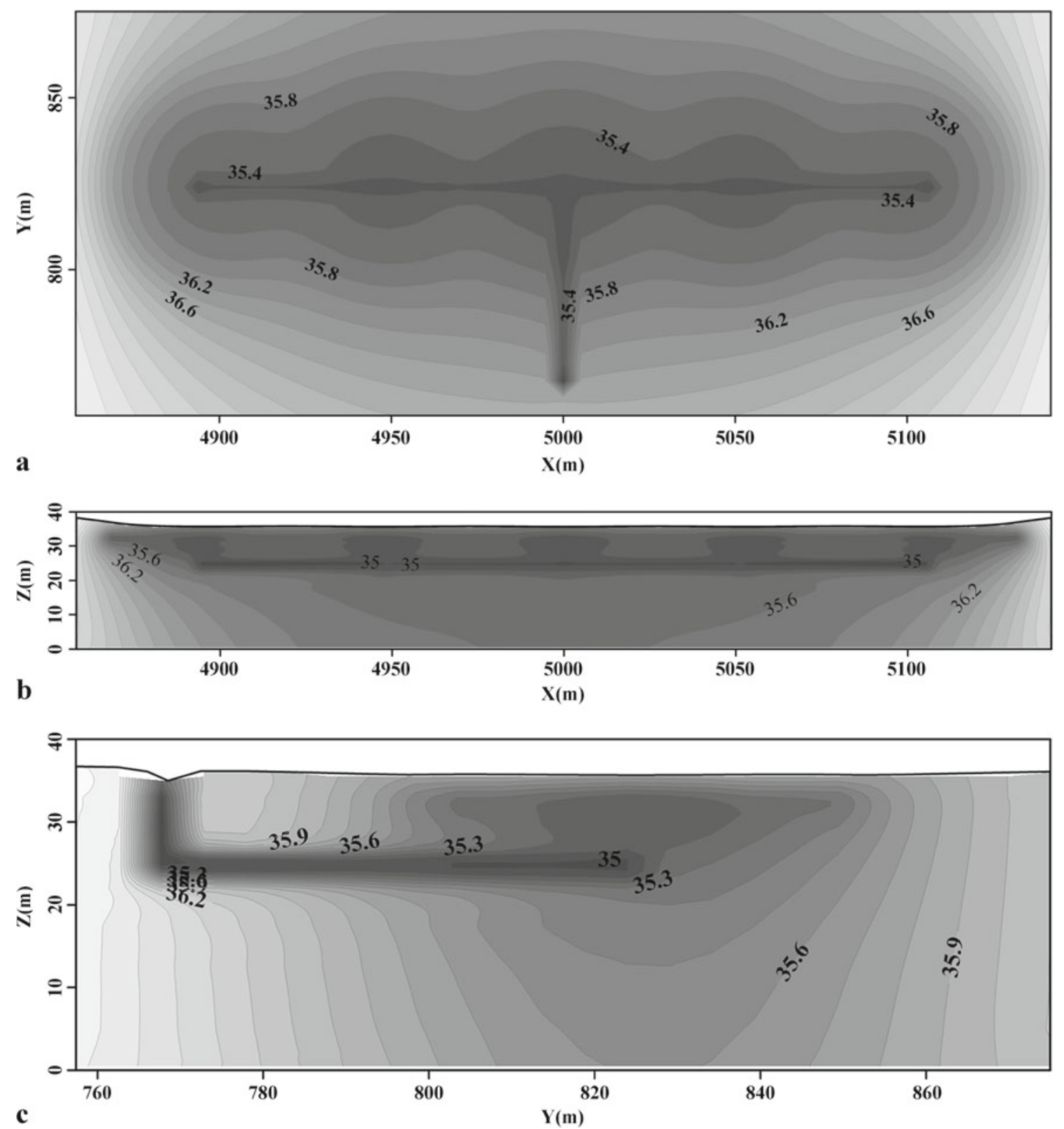

Figure 2. Hydraulic head contour map calculated by the existing model (Wang and Zhang 2007).

radiating bores are open to the Triassic rock in this model.

During the simulation, the Preconditioned Conjugate-Gradient (PCG) solver (Mary 2003) is employed for solving the groundwater flow equations. Both the head change criterion and residual criterion are $0.001 \mathrm{~m}$.

The pumpage of horizontal seepage well calculated by the modified model is $3445.78 \mathrm{~m}^{3} / \mathrm{d}$ when the drawdown of the vertical well is $5 \mathrm{~m}$. This is consistent to the pumpage calculated by the existing model, that is, $3447.70 \mathrm{~m}^{3} / \mathrm{d}$ when the drawdown of the vertical well is $5 \mathrm{~m}$. By comparison, the actual yield of the real horizontal seepage well is $3294 \mathrm{~m}^{3} / \mathrm{d}$ in total with a $4.92 \mathrm{~m}$ vertical well drawdown. This comparison proves that the proposed model is reliable in calculating the pumpage of a horizontal seepage well.

Because a weighted average hydraulic conductivity that takes into account the cross sectional areas of radiating bores is used as the vertical hydraulic conductivity in the area where the radiating bores are distributed in the existing model, and each radiating bore is depicted by a set of discrete pipes in the modified model, the water inflows of the five chambers of the horizontal seepage well calculated by the two models are slightly different. The calculated chamber inflows by the modified model are $814.67,608.43,588.02,608.43$ and $814.67 \mathrm{~m}^{3} / \mathrm{d}$, respectively. The calculated chamber inflows by the 

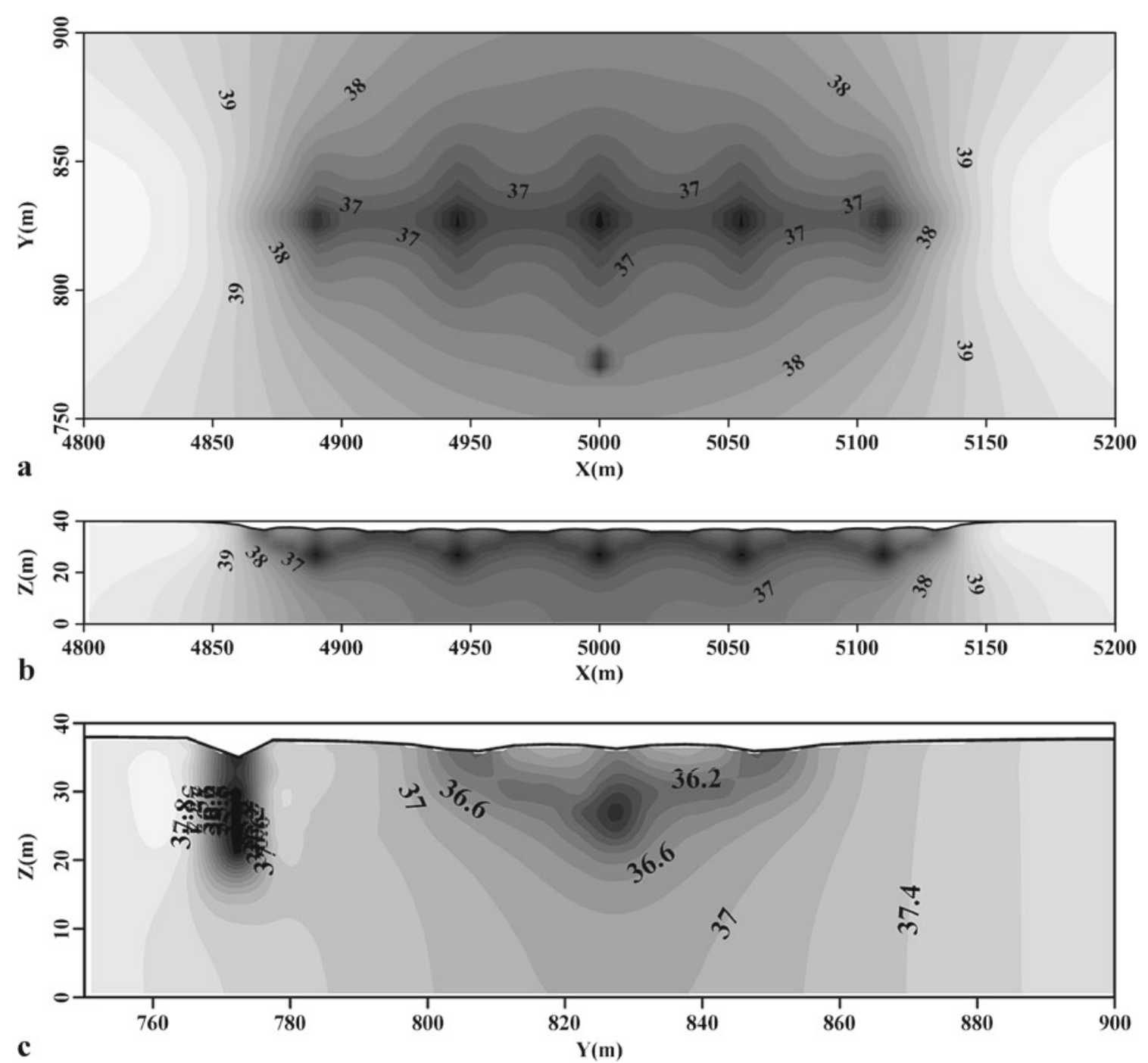

Figure 3. Hydraulic head contour map calculated by the modified model.

existing model are $722.31,675.64,643.06,675.64$ and $722.31 \mathrm{~m}^{3} / \mathrm{d}$, respectively.

The flow field of the entire domain is controlled by natural boundary and the local flow field near the horizontal seepage well is mainly controlled by the well pipe boundary (figure 3). Clearly, the modified model can depict the details of each radiating bore better than that in the existing model. Therefore, the calculated results from the modified model are more accurate and closer to actual value than those from the existing model. Figure 3 shows the steady state flow field where the galleries, chambers and vertical well are located. (a) is the plain view showing where $\mathrm{Z}$ is at $24 \mathrm{~m}$, corresponding to the center of 4th layer from the top; (b) is the cross sectional view showing where the underground chambers are located in the $\mathrm{X}$ and $\mathrm{Z}$ planes; (c) is the cross sectional view showing where the vertical well is located in the $\mathrm{Y}$ and $\mathrm{Z}$ planes. These figures indicate that groundwater flowing to the horizontal seepage well has obvious three-dimensional flow characteristics. They also show more details of flow field around the radiating bores.

Because of the more accurate depiction of the radiating bores' distribution in the modified model, the water table and hydraulic head distribution

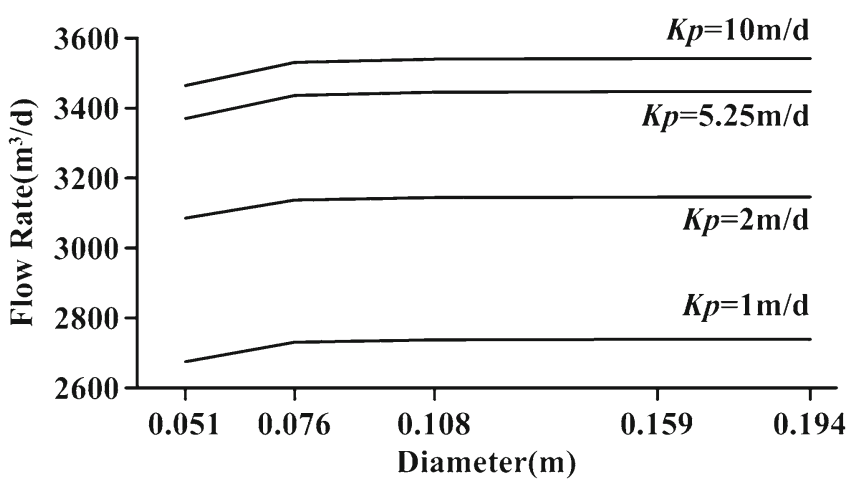

Figure 4. Relation between total yield and the diameter of radiating bore. 


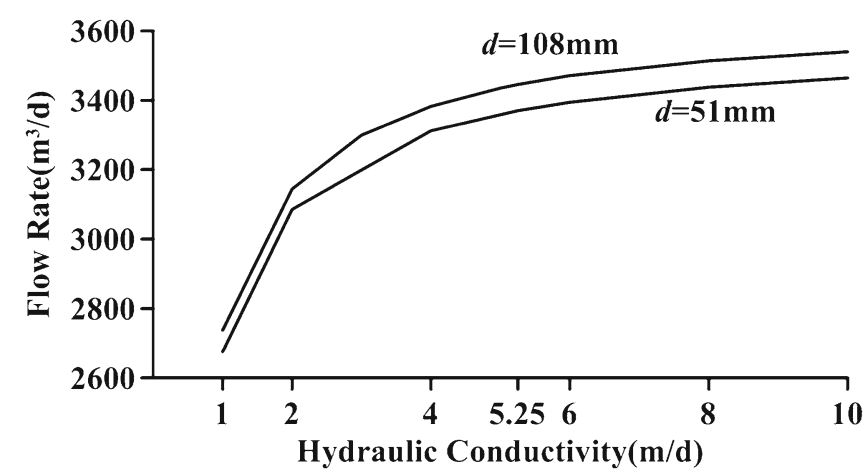

Figure 5. Relation between total yield and the hydraulic conductivity of the screen material of radiating bore.

are more complex in the modified model near the radiating bores than that in the existing model. This indicates that the modified model can better depict the flow field affected by the well pipes of horizontal seepage well. Since the well pipe is treated as part of the aquifer which is highly permeable in the existing model and the hydraulic conductivity of the aquifer where radiating bores are distributed is set as an equivalent hydraulic conductivity, hydraulic head contour map from the existing model can depict the difference between the heads in the pipes and those on the outside. However, hydraulic head contour map from the existing model cannot depict the details of the head around the aquifer where radiating bores are distributed. Since the well pipes are treated as sources and/or sinks by a set of discrete conduit network model coupled with a single continuum model, the hydraulic head contour map can only depict the head in aquifer where the well pipe is not included. However, it can depict the head change that was affected by well pipes more realistically.

The actual yield of the real horizontal seepage well, which is located in the Wulidian water-supply field in Wuding river valley of Suide city of China, is $3294 \mathrm{~m}^{3} / \mathrm{d}$ when the drawdown of the vertical well is $4.92 \mathrm{~m}$. The comparison between the calculated value by the modified model and the real value also indicates that the modified model of horizontal seepage well is reliable in calculating the pumpage of a horizontal seepage well.

\section{Advantages of the modified model over the existing model}

\subsection{Accurate depiction of the characteristics of radiating bores}

In the modified model, the radiating bores as well as galleries are treated as a set of discrete pipes connected by nodes. The characteristics of each pipe, such as the length, the diameter, the distribution, the hydraulic conductivity and the thickness of the pipe screen, and the radiating bores that are irregularly distributed can be depicted. It is easy to see that the finer the grid is, the more accurately the radiating bores can be depicted.

The effect of different radiating bore can be examined using the modified model (figure 4). In figure 4 , the letter $\mathrm{K}$ represents the hydraulic conductivity of the screen material of radiating bore. The total yield of a horizontal seepage well will increase when the diameter of radiating bores is increased. However, the increment of water yield of well is getting smaller when the well diameter is increased to the values greater than $76 \mathrm{~mm}$. Clearly, an increase in the diameter of radiating bores will increase construction cost and complexity. To be specific, the stability of radiating bore walls will be dramatically reduced during the construction process, and the total cost of horizontal seepage well will also increase. Thus, to increase the well diameter greater than $100 \mathrm{~mm}$ seems to be unwise, as indicated by the model prediction of the decreasing increment in the yield. Increasing the number of radiating bores is more likely to increase the well yield rather than increasing the

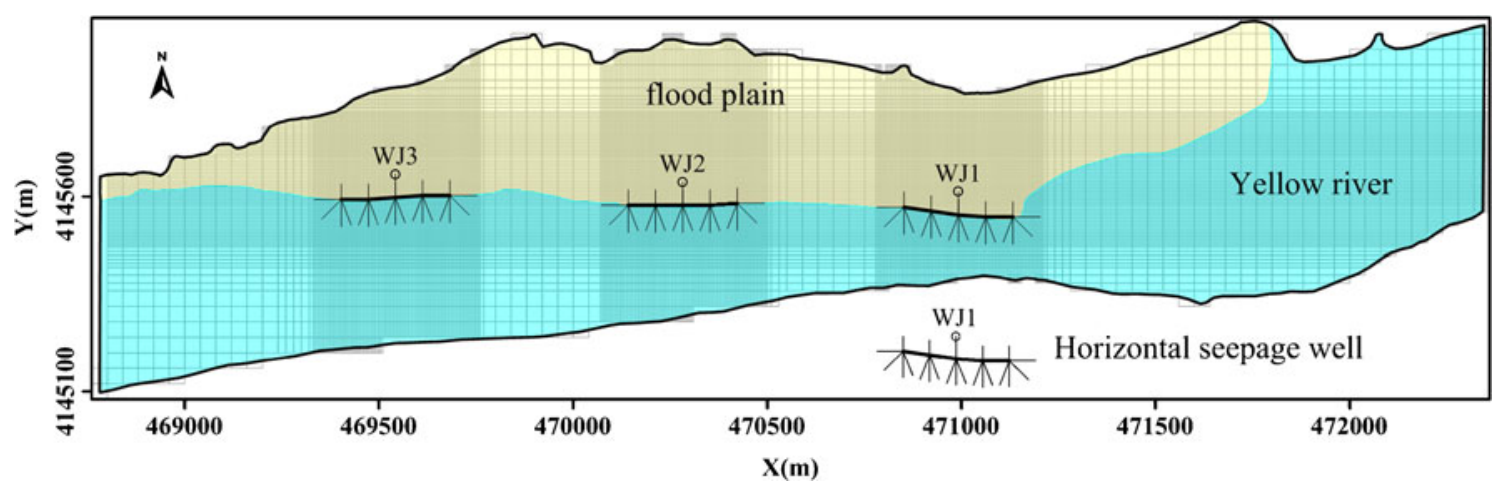

Figure 6. Location of horizontal seepage wells. The thicker line represents the galleries, and the thinner line represents the radiating bores. 

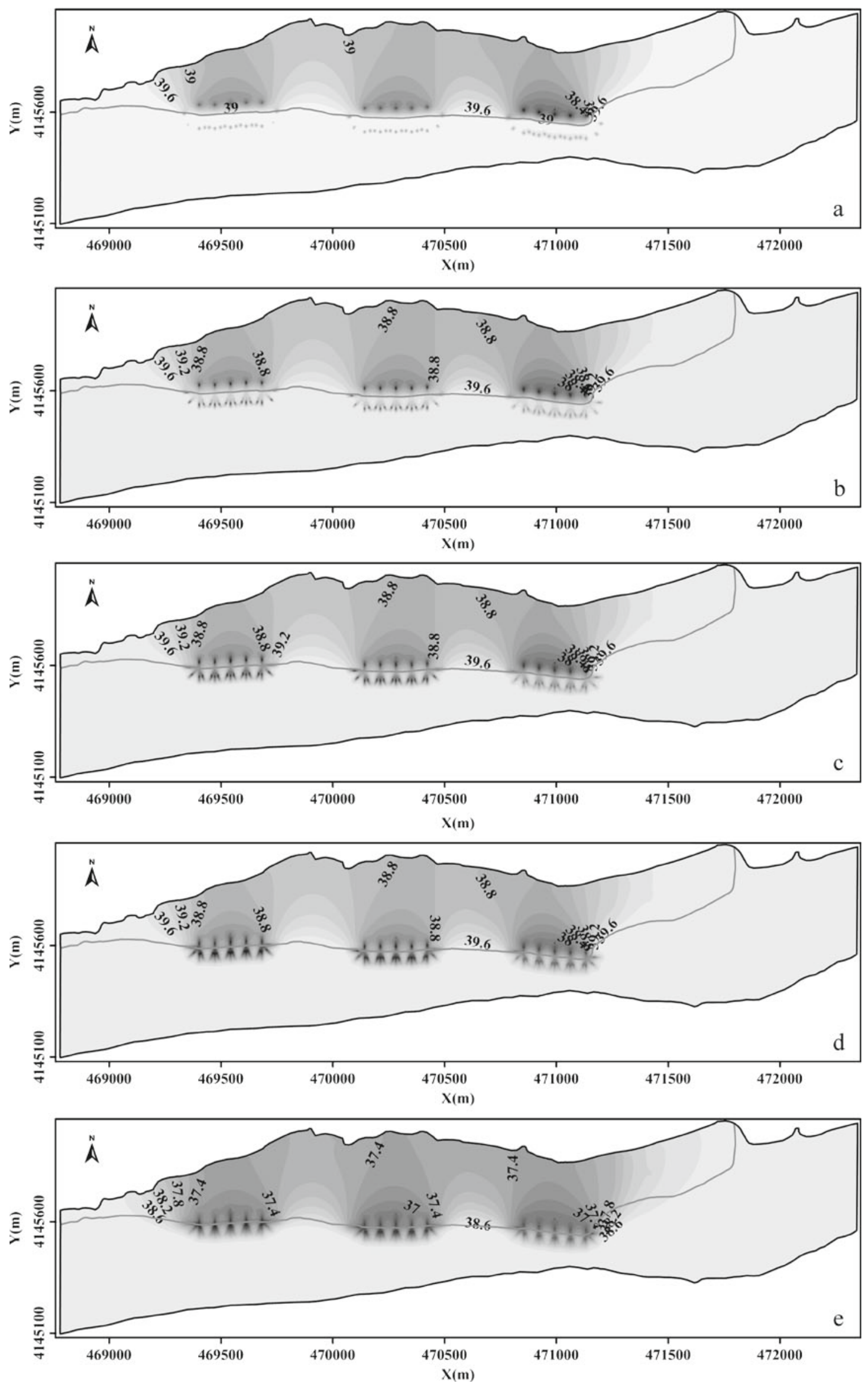

Figure 7. Horizontal sectional view of hydraulic head contour map containing three horizontal seepage wells. 

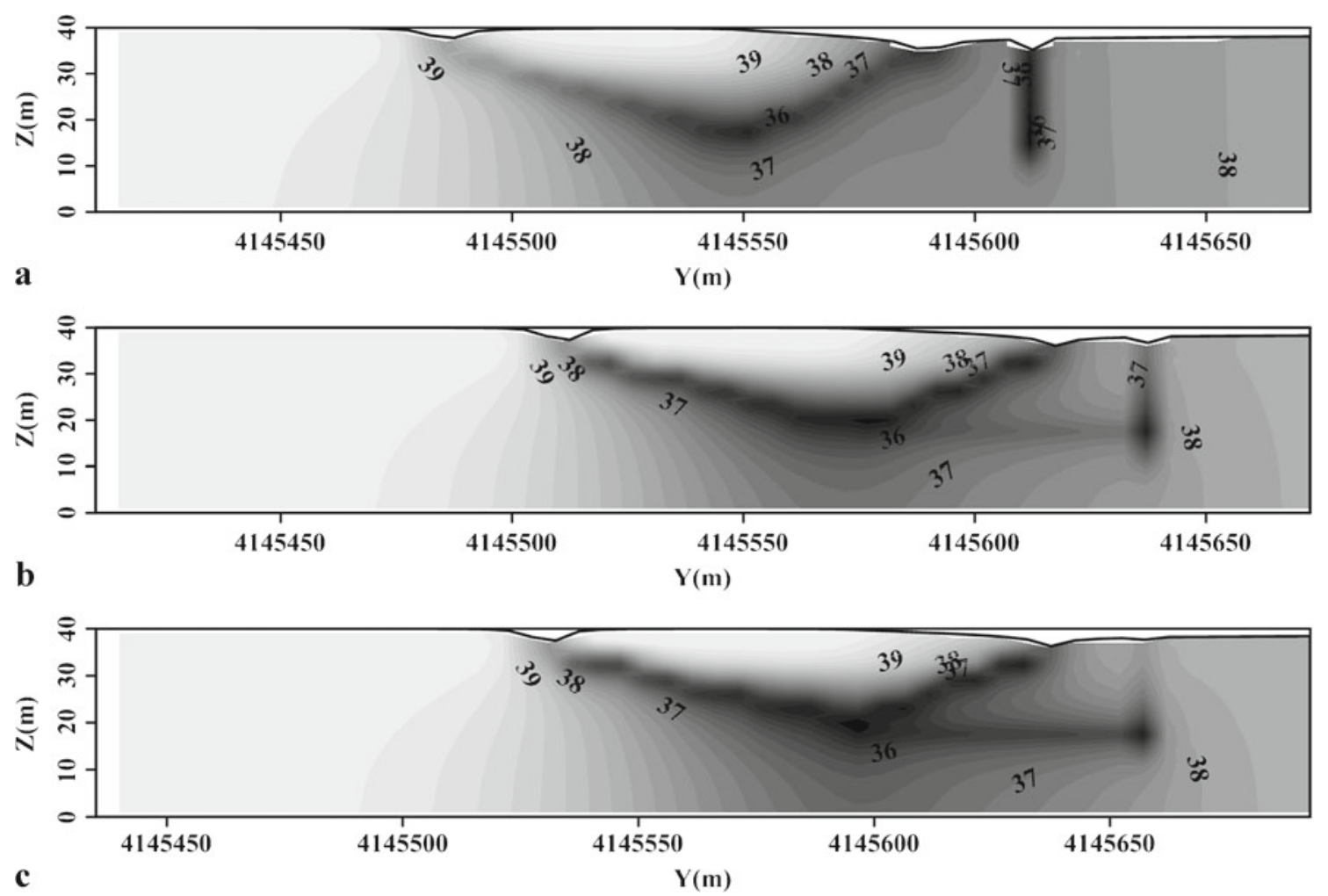

Figure 8. Cross sectional view of hydraulic head contour map, showing where the vertical well of the horizontal seepage well WJ1, W2 and W3 is located in the $\mathrm{Y}$ and $\mathrm{Z}$ planes.

diameter of radiating bores. The total yield of a horizontal seepage well can be improved when the permeability of the screen of radiating bores is getting greater (figure 5). In figure 5 , the letter ' $d$ ' represents the diameter of the radiating bore and the hydraulic conductivity of the Quaternary aquifer is $5.25 \mathrm{~m} / \mathrm{d}$. Clearly, the increased rate of total yield will decrease when the hydraulic conductivity of screen is greater than that of the aquifer. The screen with permeability higher than that of the aquifer should be adopted. If the bores with smaller diameter can be kept stable, an uncasing bore as the radiating bore should be adopted.

\subsection{Calculation of the scenario in which several horizontal seepage wells work together}

As more and more water-supplying fields accept the water-collecting structure of horizontal seepage, there are always several horizontal seepage wells working together in one water-supplying field. Thus, it is necessary to build a model which can describe the interactions among all horizontal seepage wells to evaluate the interference between two adjacent horizontal seepage wells.

In this study, three horizontal seepage wells in a water-supply field near the Yellow River of China are simulated. The model domain is about $3700 \mathrm{~m}$
$\mathrm{E}-\mathrm{W}$ and $700 \mathrm{~m} \mathrm{~N}-\mathrm{S}$, and the width of the river is 200-700 m. The model domain can be discretized into 99 columns, 41 rows, and 11 layers with the minimum interval of $5 \mathrm{~m}$ in the horizontal plane near the horizontal seepage well (figure 6). The distance between two adjacent horizontal seepage wells is about $700 \mathrm{~m}$. The radiating bores of horizontal seepage well were irregularly distributed (figure 6). Because the horizontal seepage wells span over most of the model domain, both natural boundary and well pipe boundary have great influence on hydraulic head distribution. The plane view of flow fields at different depths are shown in figure 7 where a, b, c, d and e show where $\mathrm{Z}$ is at 37 , $32.5,29.5,26.5$ and $23.5 \mathrm{~m}$ which are corresponding to the center of the top layer, the second layer, the third layer, the fourth layer and the fifth layer from the top, respectively. Figure 8 shows the cross sectional flow field for horizontal seepage wells where the vertical well is located. As the hydraulic conductivity of Triassic rock near the horizontal seepage well WJ1 is far greater than that of the lining material of the main gallery; the main gallery has little influence on the flow field (figure 8).

Since the width of the Yellow River is about 200-500 $\mathrm{m}$ and the water depth is about $2 \mathrm{~m}$, the Yellow River has great potential leakage ability. According to the calculation results, when the drawdown of vertical well is $4 \mathrm{~m}$, the pumpage of 
three horizontal seepage wells which are working separately is $7749.99,4602.71$ and $4254.35 \mathrm{~m}^{3} / \mathrm{d}$, respectively, and the pumpage of three horizontal seepage wells which are working simultaneously is $7742.43,4600.26$ and $4252.52 \mathrm{~m}^{3} / \mathrm{d}$ respectively. It is indicated that the interference between two adjacent horizontal seepage wells is small when the well spacing is about $700 \mathrm{~m}$.

\section{Conclusion}

This paper presents a modified model, in which the method of coupling a single continuum model with a discrete conduit network model is adopted instead of treating the well pipe as a highly permeable medium. This method can overcome the limitations of the existing model. Turbulent flow inside the horizontal seepage well is coupled with the laminar flow in the aquifer using the exchange flow rate between well pipe and aquifer as the couple key. The flow rate in the well pipe can be calculated based on the Reynolds numbers inside the well pipe. Laminar, transitional, and turbulent flow regimes that occurred inside the horizontal seepage well are also well considered.

Through comparing the calculated yield by the modified model and the calculated yield by the existing model and also the actual yield of the real horizontal seepage well, it is proved that the modified model is reliable in calculating the pumpage of a horizontal seepage well.

Case studies show that the modified model can accurately depict the characteristics of radiating bores, including the diameter, the permeability of screen material as well as the hydraulic interactions among several horizontal seepage wells even for areas where the radiating bores are irregularly distributed.

Further analysis shows that increasing the number of radiating bores rather than the diameter and using the screen with permeability higher than that of aquifer are more likely to increase the well yield.

\section{Acknowledgements}

This research is sponsored by both National Natural Science Foundation of China (Grant \#40502025, \#40972154) and Chang'an University
Development Foundation of Science and Technology (Grant \#05Q12).

\section{References}

Adams R and Parkin G 2002 Development of a surfacegroundwater-pipe network model for the sustainable management of karstic groundwater; Environ. Geol. 42(5) 513-517.

Bear J 1972 Dynamics of fluids in porous media; Elsevier, New York.

Chen C 1995 Study of ground water flow model and simulation in three-porosity system of karst channel-fractureporous medium (in Chinese); Earth Sci. J. China Univ. Geosci. 20(4) 361-366.

Chen C and Lin M 1998a Groundwater flow model of mixed well and its application (in Chinese); Publishing House of China, University of Geosciences, Wuhan, China.

Chen C and Lin M 1998b Groundwater hydraulics (in Chinese); Publishing House of China, University of Geosciences, Wuhan, China.

Chen C and Jiao J 1999 Numerical simulation of pumping test in multilayer wells with non-Darcian flow in the wellbore; Ground Water 37(3) 465-474.

Chen C, Wan J and Zhan H 2003 Theoretical and experimental studies of coupled Darcian-pipe flow to a horizontal well; J. Hydrol. 281(1-2) 163-175.

Clemens T, Hùkinghaus D, Sauter M, Liedl R and Teutsch G 1996 A combined continuum and discrete network reactive transport model for the simulation of karst development; In: Calibration and reliability in groundwater modeling. Proceedings of the ModelCARE 96 Conference, Golden, Colo., IAHS Publ. 237 309-318.

Fu Ling, Fang Xi, Zhang Liping and Zhang Gehong 2004 Water intake design of seepage wells for a county; Water and Waste Water 30(7) 27-30 (in Chinese).

$\mathrm{Li} \mathrm{W}$ and $\mathrm{Xu}$ X 2000 Hydraulics (in Chinese); Publishing House of Wuhan Water Resources and Hydropower University, Wuhan, China.

Li Xiao and Yang Lizhong 2003 A new water-gathering technique using the infiltration of natural riverbed; China Water and Waste Water 19(6) 74-76 (in Chinese).

Mary C Hill 2003 Preconditioned conjugate-Gradient 2 (PCG2), a computer program for solving ground-water flow equations; U.S. Geological Survey Water-Resources Investigation Report 90-4048, Denver, Colorado, USA.

Munson B R, Young D F and Okiishi T H 1998 Fundamentals of Fluid Mechanics, 3rd edn, Wiley, New York, USA.

Shoemaker W B, Kuniansky E L, Birk S, Bauer S and Swain E D 2007 Documentation of a Conduit Flow Process (CFP) for MODFLOW-2005; U.S. Geological Survey Techniques and Methods, 6-A24, Reston, Virginia, USA.

Steffen Mehl 2006 Use of picard and newton iteration for solving nonlinear groundwater flow equations; Ground Water 44(4) 583-594.

Wang W and Zhang G 2007 Numerical simulation of groundwater flowing to horizontal seepage wells under a river; Hydrogeol. J. 15 1211-1220. 